\title{
Stress-related and diurnal alcohol drinking in rats*
}

\author{
GLENN I. HATTON and ALLEN VIETH \\ Michigan State University, East Lansing, Michigan 48823
}

\begin{abstract}
Recording ethanol intakes $24 \mathrm{~h} /$ day for rats which experienced shock avoidance sessions during the light portion of a 14L:10D cycle showed that: (a) animals drank immediately after coming back to the home cage, but not before or during the sessions; (b) dark onset was followed by a sharp increase in intake, declining towards light onset for alcohol but not for water. The amounts and times of ethanol intake suggest that corticosterone may mediate stress-related ethanol preference in rats.
\end{abstract}

A relationship between ethanol consumption and carefully administered stressors has been established for many animal species, in part as a search for an appropriate animal model for the study of alcohol abuse in man (Cicero, Myers, \& Black, 1968; Clark \& Polish, 1960; Rodgers \& Thiessen, 1964; von Wright, Pekanmäki, \& Malin, 1971). One of these species, the rat, has been the subject of much recent research along these lines (Myers \& Veale, 1972); however, the precise ways in which the stressed state of the animal induce ethanol drinking are obscure and the temporal relationships between the consumption of ethanol and the stress are largely unknown. For example, previous studies have shown that the daily intake of ethanol increases when a learned signal for shock avoidance is followed by shock whether or not the animal makes the heretofore appropriate avoidance response (Cicero et al, 1968). Also, even though ethanol is freely available in the noxious situation, $100 \%$ of the consumption occurs in the presence of safe cues, e.g., in the home cage (Opsahl \& Hatton, 1972). This finding suggested that the rat might prefer its "strong drink" at the end of its ordeal rather than during it. The possibility remained, however, since the only data available were for 24-h time chunks, that animals may anticipate the occurrence of regularly scheduled stressors and imbibe in anxious anticipation of such sessions. Finally, no information was available concerning the hour-by-hour diurnal rhythm of ethanol drinking, particularly in stressed rats.

\section{METHOD}

The Ss were three adult male albino rats of the Holtzman strain, approximately 100 days old at the start of the experiment. They were maintained in standard metabolism cages, at $21^{\circ}-23^{\circ} \mathrm{C}$ room temperature and on a $14 \mathrm{~L}: 10 \mathrm{D}$ light-dark cycle. Powdered Wayne Mouse Breeder Blox were continuously available in the home cage. Also available were tap water and $7.5 \%$ ethanol in inverted graduated cylinders fitted with glass spouts. A third, empty glass-spouted cylinder was also muunted on the cage; the three cylinders were randomly rotated in order to eliminate position preferences (Myers \& Holman, 1966). Leverpress avoidance training was given in three Lehigh

*This research was supported by N.I.H. Research Grant NS09140 and Biomedical Sciences Support Grant 07049, and also by Research Career Development Award 1K04 GM22,680 to G. I. Hatton.
Valley operant chambers, in which tap water and $7.5 \%$ ethanol were also available. These chambers were located in a room remote from the one in which the rats were housed. Home cage drinking of both water and ethanol were monitored with drinkometers $24 \mathrm{~h}$ per day.

\section{Procedure}

Animals were adapted to the metabolism cages and to the ethanol solution for at least 2 weeks; then they were given familiarization experience in the operant boxes. During this time, all rats drank from both the ethanol and water spouts in the boxes. Following this, the rats were given barpress avoidance training for $60 \mathrm{~min}$ per day, 5 days per week. These sessions generally occurred from $0900-1000 \mathrm{~h}$. On the remaining 2 days of the week, no avoidance sessions were given but the $\mathrm{E}$ who always gave the avoidance training came into the room and recorded intake and weight data, replenished ethanol water and food, etc. Days on which avoidance training occurred are termed avoidance days; those days when the avoidance training $\mathrm{E}$ merely carried out the routine maintenance tasks are termed nonavoidance days. Upon noting that the rats began drinking ethanol on the nonavoidance days when the familiar $\mathrm{E}$ was present, we instituted what we call nonstress days: a sequence of 4 days on which an unfamiliar $E$ carried out the routine maintenance tasks.

\section{RESULTS AND DISCUSSION}

\section{Stress-Related Drinking}

First, no rat ever drank in the operant chamber after the start of avoidance training, thus replicating our earlier findings (Opsahl \& Hatton, 1972). In Fig. 1 it can be seen that the drinking of both ethanol and water follows the stress period on avoidance days. It neither anticipates nor does it occur during the avoidance session as a sort of self-administered anesthesia. Further, $75 \%$ of the ethanol and $64 \%$ of the water consumed during lights-on occurred during the first 2 postsession hours on avoidance days. Earlier studies (Cicero et al, 1968; Opsahl \& Hatton, 1972) contained no information regarding this temporal distribution of intakes related to stress. Alcohol preference during the postsession lights-on period of the day was directly related to the severity of the stress. That is, the mean ethanol intake as a percentage of total intake was $34 \%$ on avoidance days, was only $23 \%$ on nonavoidance days, and fell to $10 \%$ on nonstress days, with all rats showing decreased preference. It appears from these data that the stress response produced by the shock sessions is generalized 


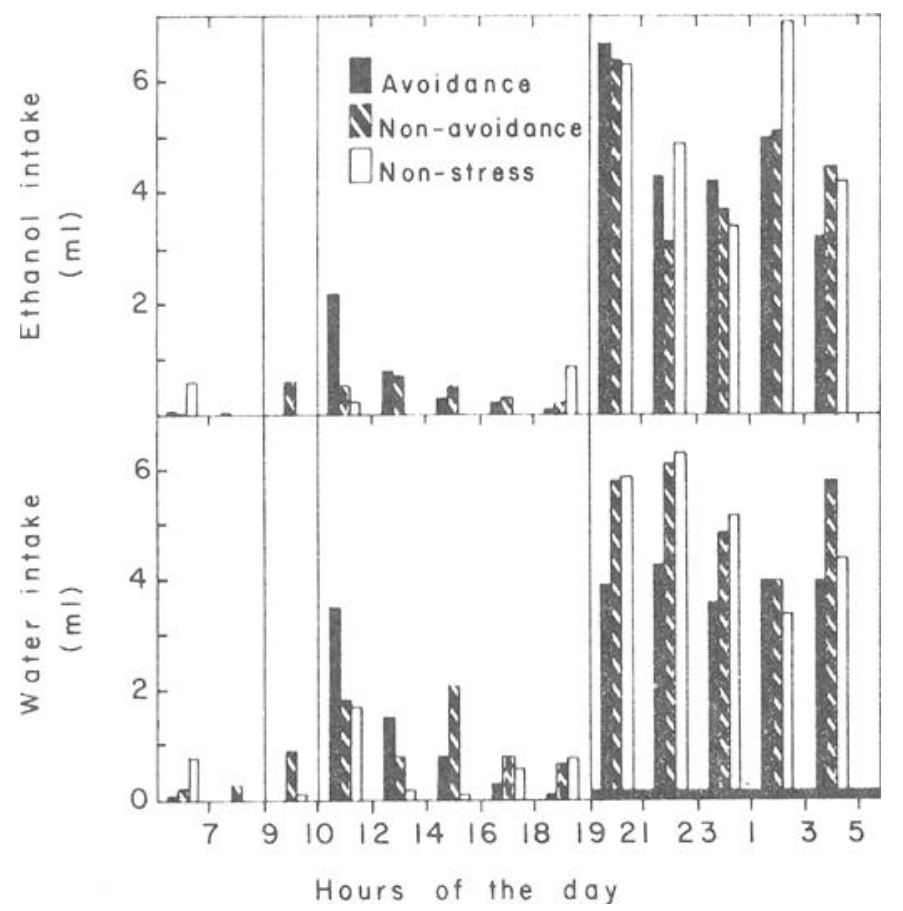

Fig. 1. (top) Ethanol intakes under three experimental conditions which may be ordered in terms of stressfulness: Avoidance days $>$ Non-avoidance days $>$ Non-stress days. (bottom) Water intakes under the same conditions as for ethanol intakes. Black horizontal bar indicates lights off. Along the baseline are the hours of the day, grouped in two-hour blocks except for 9-10 and 18-19. The 9-10 hour block was the time when avoidance training was given; the 18-19 hour block is plotted separately for convenience, since our light period contained an even number of hours. (with some decrement) to the $\mathrm{E}$ administering the sessions, and that this generalized response is reflected in ethanol preference.

\section{Diurnal Drinking}

Three things concerning the diurnal drinking of ethanol are noteworthy: (a) there was a copious consumption with a sharp onset starting immediately after lights-out, just as there was with water; (b) ethanol drunk on the avoidance days during lights-on did not diminish intake of ethanol in the dark, whereas the water consumed on these days did appear to subtract from the water drunk during the lights-off period; and (c) for all rats on avoidance days, ethanol intakes but not water intakes were highest immediately after lights-out and declined nonmonotonically with time, being lowest during the $0300-0500$ period.

These findings and those of previous studies of stress-related ethanol drinking suggest to us that some hormonal component of the stress response plays a role in mediating ethanol preference. Corticosterone, which is released during stress, is a likely candidate here because it is long-acting enough to account for the postsession intakes and it shows a diurnal cycle with a peak at or near lights-out (Critchlow, 1963; Krieger, 1972). Further, it shows a nonmonotonic decline toward the end of the active period in man (Weitzman, Fukushima, Nogiere, Roffwarg, Gallagher, \& Hellman,
1971) and possibly in rat, though this fine analysis of hour-by-hour corticosterone levels has not been accomplished for rats.

\section{REFERENCES}

Cicero, T. J., Myers, R. D., \& Black, W. C. Increase in volitional ethanol consumption following interference with a learned avoidance response. Physiology \& Behavior, 1968, 3, 657-660.

Clark, R., \& Polish, E. Avoidance conditioning and alcohol consumption in rhesus monkeys. Science, 1960, 132, 223-224.

Critchlow, $V$. The role of light in the neuroendocrine system. In A. V. Nalbandov (Ed.), Advances in neuroendocrinology. Urbana, Ill: University of Illinois Press, 1963. Pp. 377-402.

Krieger, D. T. Circadian corticosteroid periodicity: Critical period for abolition by neonatal injection of corticosteroid. Science, 1972, 178, 1205-1207.

Myers, R. D., \& Holman, R. B. A procedure for eliminating position habit in preference-aversion tests for ethanol and other fluids. Psychonomic Science, 1966, 6, 235-236.

Myers $R$. D. \& Veale, W. L. The determinants of alcohol preference in animals. In B. Kissin and H. Begleiter (Eds.), The biology of alcoholism. Vol. II. New York: Plenum, 1972. Pp. 131-168.

Opsahl, C. A., \& Hatton, G. I. Volitional increases during acquisition and extinction of avoidance responding. Physiology \& Behavior, 1972, 8, 87-93.

Rodgers, D. A., \& Thiessen, D. D. Effects of population density on adrenal size, behavioral arousal, and alcohol preference of inbred mice. Quarterly Journal of Studies on Alcohol, 1964, 25, 240-247.

von Wright, J. M., Pekänmaki, L., \& Malin, S. Effect of conflict and stress on alcohol consumption in rats. Quarterly Journal of Studies on Alcohol, 1971, 32, 420-433.

Weitzman, E. D., Fukushima, D., Nogiere, C., Roffwarg, H., Gallagher, T. F., \& Hellman, L. Twenty-four hour pattern of the episodic secretion of cortisol in normal subjects. Journal of Clinical Endocrinology \& Metabolism, 1971, 33, 14-22.

(Received for publication June 6, 1974.) 